\title{
The Sinorhizobium meliloti chromosomal origin of replication
}

Correspondence

Turlough M. Finan

finan@mcmaster.ca

Received 18 August 2005

Revised 17 October 2005

Accepted 31 October 2005
Christopher D. Sibley, Shawn R. MacLellan and Turlough Finan

Center for Environmental Genomics, Department of Biology, McMaster University, 1280 Main St West, Hamilton, Ontario, Canada L8S 4K1

The predicted chromosomal origin of replication (oriC) from the alfalfa symbiont Sinorhizobium meliloti is shown to allow autonomous replication of a normally non-replicating plasmid within S. meliloti cells. This is the first chromosomal replication origin to be experimentally localized in the Rhizobiaceae and its location, adjacent to hemE, is the same as for oriC in Caulobacter crescentus, the only experimentally characterized alphaproteobacterial oriC. Using an electrophoretic mobility shift assay and purified $S$. meliloti DnaA replication initiation protein, binding sites for DnaA were mapped in the $S$. meliloti oriC region. Mutations in these sites eliminated autonomous replication. S. meliloti that expressed DnaA from a plasmid lac promoter was observed to form pleomorphic filamentous cells, suggesting that cell division was perturbed. Interestingly, this cell phenotype is reminiscent of differentiated bacteroids found inside plant cells in alfalfa root nodules.

\section{INTRODUCTION}

Bidirectional replication of the bacterial chromosome requires the specific interaction of the ATPase DnaA at a precise region on the replicon, termed the chromosomal origin of replication (oriC) (Fuller et al., 1981, 1984). oriC is the location of the initial strand opening event that precedes replication and the site of replisome assembly (Bramhill \& Kornberg, 1988b). Many of the molecular events that occur at the Escherichia coli oriC have been well characterized, providing a general model of the essential biochemical process which results in the formation of two replication forks and duplication of oriC (Bramhill \& Kornberg, 1988a). While E. coli oriC is the most extensively characterized chromosome origin, sequences capable of autonomous replication have been isolated from many bacterial chromosomes (Harding et al., 1982; Zyskind et al., 1983; Yee \& Smith, 1990; Zakrzewska-Czerwinska \& Schrempf, 1992; Fujita et al., 1990, 1992; Calcutt \& Schmidt, 1992; Schaper et al., 2000; Moriya et al., 1992; Salazar et al., 1996; Jakimowicz et al., 1998). In most sequenced bacterial chromosomes, oriC has been predicted on the basis of sequence analysis where a switch in the asymmetry of the two strands of DNA coincides with the origin and terminus of the chromosome (Lobry, 1996). The architecture of the bacterial chromosome origin is nevertheless diverse with respect to the physical sequence as well as the number and organization of binding sites for proteins that control the timing of origin firing. Binding sites for the replication initiator DnaA (DnaA boxes) appear to be one of the hallmark features of bacterial chromosome origins and because of this the location of DnaA boxes in the bacterial genome has been used as a method for predicting oriCs (Mackiewicz et al., 2004). Another feature of many functional origins is that adjacent to the DnaA boxes is an exceptionally AT-rich region which is the site of initial strand separation. Bacterial chromosome origins are commonly located in close vicinity to the $d n a A$ gene and attempts have been made to exploit this linkage in the cloning of oriCs (Smith et al., 1991; Fujita et al., 1990, 1992; Schaper et al., 2000; Moriya et al., 1992; Salazar et al., 1996; Jakimowicz et al., 1998). Examples do exist in which hallmarks of oriCs have not been found to be linked to the $d n a A$ replication initiation gene, such as the chromosomes of Synechocystis spp. (Richter \& Messer 1995), Prochlorococcus marinus (Richter et al., 1998) and Sinorhizobium meliloti (Margolin et al., 1995).

S. meliloti is a Gram-negative bacterium that forms root nodules on alfalfa. The colonization of alfalfa roots by $S$. meliloti provokes a complex differentiation program resulting in morphological changes in both organisms. Nitrogenfixing bacteroids have been reported to contain more nucleic acid per cell than the free-living form and thus may undergo a process of endoreduplication within alfalfa (Paau et al., 1977). It is unclear what role DNA replication of the S. meliloti genome has during differentiation; however, the origins of replication in the $S$. meliloti genome may serve as important elements that coordinate this process within plant cells. The tripartite genome of S. meliloti (Galibert et al., $2001)$ is composed of a circular chromosome $(3.6 \mathrm{Mb})$ and two megaplasmids, pSymA $(1.35 \mathrm{Mb})$ and pSymB $(1.68 \mathrm{Mb})$. Previously, the chromosomal origin was predicted to be located adjacent to the hemE gene (encoding uroporphyrinogen decarboxylase) on the basis of DNA 
strand asymmetry (Capela et al., 2001). Here we show that a DNA fragment encompassing this region can confer autonomous replication to a non-replicating plasmid and that these minichromosomes are maintained in S. meliloti at copy numbers of less than one per host chromosome. Using a combined bioinformatic, genetic and biochemical approach we have mapped essential DnaA-binding sites within oriC. We previously characterized the replication origins from both megaplasmids carried by $S$. meliloti (Chain et al., 2000; MacLellan et al., 2005) and this work completes our initial characterization of the third origin of replication carried by this bacterium.

\section{METHODS}

Bacterial strains and plasmids. The bacterial strains used in this study are listed in Table 1. E. coli was grown at $37^{\circ} \mathrm{C}$ in LB broth and S. meliloti was grown at $30^{\circ} \mathrm{C}$ in $\mathrm{LB}$ supplemented with $2.5 \mathrm{mM} \mathrm{MgSO}_{4}$ and $2.5 \mathrm{mM} \mathrm{CaCl}_{2}$ ( $\mathrm{LBmc}$ ) or on $\mathrm{LB}$ solidified with agar $\left(16 \mathrm{~g} \mathrm{l}^{-1}\right)$.

Table 1. Bacterial strains and plasmids

\begin{tabular}{|c|c|c|}
\hline Plasmid & Genotype or characteristics & Source or reference \\
\hline pET431a & Ap $^{\mathrm{R}}$, NusAHis6 tag expression vector, inducible with IPTG & Novagen \\
\hline pRK600 & pRK2013 npt::Tn9; $\mathrm{Cm}^{\mathrm{R}}$ & Finan et al. (1986) \\
\hline pBBR1MCS-5 & $\mathrm{Gm}^{\mathrm{R}}$, broad host-range cloning vector, LacZ $\alpha$ peptide & Kovach et al. (1995) \\
\hline pUCP30T & $\mathrm{Gm}^{\mathrm{R}}$, ColEI oriV cloning vector, oriT & Schweizer et al. (1996) \\
\hline pTH838 & $\begin{array}{l}\text { pUCP30T with } 3 \mathrm{~kb} \text { oriC (AB24853-AB24854) cloned via EcoRI, hemE } \\
\text { same orientation as Plac }\end{array}$ & This work \\
\hline pTH879 & 710 bp HindIII-SalI oriC fragment cloned into pUCP30T & This work \\
\hline рТН880 & 875 bp BamHI-SalI oriC fragment cloned into pUCP30T & This work \\
\hline pTH881 & 861 bp SacII oriC fragment cloned into pMB439 suicide plasmid & This work \\
\hline pTH1081 & pET431a with dnaA (AB26340-AB26341) cloned via BamHI/EcoRI & This work \\
\hline рТН1091 & $\begin{array}{l}\text { PBBR1MCS-5 with } d n a A \text { and ribosome-binding site (AB29744-AB29675) } \\
\text { cloned via } \mathrm{XbaI} / \mathrm{SacI} \text {, same orientation as Plac }\end{array}$ & This work \\
\hline pTH1205 & $\begin{array}{l}\text { pTH838 with } 3 \text { bp deletion in DnaA box \#1 TCATCCGCC } \rightarrow \text { TCCGCC, } \\
\text { created via site-directed mutagenesis (AB31447-AB31448) }\end{array}$ & This work \\
\hline pTH1206 & $\begin{array}{l}\text { pTH838 with } 4 \text { bp deletion in DnaA box \#2 TCATCCACA } \rightarrow \text { TCACA, } \\
\text { created via site-directed mutagenesis (AB31449-AB31450) }\end{array}$ & This work \\
\hline рTH1207 & $\begin{array}{l}\text { pTH838 with } 4 \text { bp deletion in DnaA box \#3 TTGTCCACA } \rightarrow \text { TTGTA, } \\
\text { created via site-directed mutagenesis (AB31451-AB31452) }\end{array}$ & This work \\
\hline pTH1245 & $\begin{array}{l}\text { pUCP30T with } 483 \text { bp hemE-Y02793 intergenic region (AB32323-AB32324) } \\
\text { cloned via EcoRI }\end{array}$ & This work \\
\hline pTH1253 & $\begin{array}{l}\text { pTH838 with } 4 \text { bp deletion in DnaA box \#4 TTATCAACA } \rightarrow \text { CAACA, } \\
\text { created via site-directed mutagenesis (AB32750-AB32751) }\end{array}$ & This work \\
\hline рTH1416 & pUCP30T with 2289 bp oriC (ML1817-ML1818) cloned via EcoRI & This work \\
\hline рTH1442 & pUCP30T with 2472 bp oriC (ML1817-AB24853) cloned via EcoRI & This work \\
\hline pTH1443 & pUCP30T with 2823 bp oriC (ML1818-AB24854) cloned via EcoRI & This work \\
\hline pTH1451 & pUCP30T with 2402 bp oriC (ML2444-ML1818) cloned via EcoRI & This work \\
\hline рTH1452 & pUCP30T with 2421 bp oriC (ML2443-ML1818) cloned via EcoRI & This work \\
\hline pTH1453 & pUCP30T with 1783 bp oriC (ML2444-ML2445) cloned via EcoRI & This work \\
\hline pTH1454 & pUCP30T with 1802 bp oriC (ML-2443-ML2445) cloned via EcoRI & This work \\
\hline \multicolumn{3}{|l|}{ Strain } \\
\hline E. coli $\mathrm{DH} 5 \alpha$ & $\begin{array}{l}\mathrm{F}^{-} \text {endA1 hsdR17 }\left(\mathrm{r}_{\mathrm{K}}^{-}, \mathrm{m}_{\mathrm{K}}^{-}\right) \text {supE44 thi-1 recA1 gyrA96 relA1 } \Delta(\operatorname{argF-lacZYA}) \\
\mathrm{U} 169 \text { Ф80dlacZ } \Delta \mathrm{M} 15\end{array}$ & BRL \\
\hline E. coli MT616 & MM294A recA-56 (pRK600) & Finan et al. (1986) \\
\hline E. coli MT620 & MM294A recA-56 $\mathrm{Rf}^{\mathrm{R}}$ & Strain collection \\
\hline E. coli BL21 STAR & $\mathrm{F}^{-}$ompT hsdSB $\left(\mathrm{r}_{\mathrm{B}}^{-}, \mathrm{m}_{\mathrm{B}}^{-}\right)$gal dcm rne131 (DE3) & Stratagene \\
\hline S. meliloti Rm1021 & SU47 str-27 & Meade et al. (1982) \\
\hline S. meliloti Rm5004 & $\operatorname{Rm} 1021$ recA:: Tn5 & Strain collection \\
\hline S. meliloti K569 & G212 Ф pTH1044 & Strain collection \\
\hline S. meliloti $\mathrm{K} 1012$ & Rm5004(pTH838) small colony & This work \\
\hline S. meliloti K1013 & Rm5004(pTH838) large colony & This work \\
\hline
\end{tabular}


Bacterial matings. Plasmids were transferred from E. coli (donor) cells to S. meliloti (recipients) in triparental matings using MT616, a helper strain that carries transfer functions on pRK600. Strains used in the triparental mating were grown overnight and then washed twice with saline. The E. coli donor and recipient cells were adjusted to have twice the cell density as the $S$. meliloti recipient. Equal volumes of cells $(20 \mu \mathrm{l})$ were spotted onto an LB agar plate and incubated overnight at $30^{\circ} \mathrm{C}$. The mating spot was resuspended in $0 \cdot 85 \% \mathrm{NaCl}$, serially diluted and $100 \mu \mathrm{l}$ volumes were plated on LB with antibiotic to select for the $S$. meliloti recipient cells $(200 \mu \mathrm{g}$ streptomycin $\mathrm{ml}^{-1}$ ) and on LB plates containing antibiotics used to select for the recipient and the transferred test plasmid $(200 \mu \mathrm{g}$ streptomycin $\mathrm{ml}^{-1}$ and $60 \mu \mathrm{g}$ gentamicin $\mathrm{ml}^{-1}$ ). E. coli MT620 recipients were selected for on LB plates containing $20 \mu \mathrm{g}$ rifampicin $\mathrm{ml}^{-1}$ and transconjugants on LB plates containing $20 \mu \mathrm{g}$ rifampicin $\mathrm{ml}^{-1}$ and $10 \mu \mathrm{g}$ gentamicin $\mathrm{ml}^{-1}$.

General molecular biology. Plasmid DNA isolation, genomic DNA isolation, restriction analysis, PCR and site-directed mutagenesis were all performed according to standard protocols. PCR products were purified using QIAquick spin columns (Qiagen). Sequencing and primer synthesis was performed at the Mobix Central Facility (McMaster University, Hamilton, Ontario, Canada) using the ABIPRISM 3100 Genetic Analyser using the BigDye terminator chemistry.

Copy number determination. Total DNA was prepared from cultures grown to an $\mathrm{OD}_{600}$ of $0 \cdot 5-0 \cdot 6$, according to a standard protocol. Genomic DNA $(10 \mu \mathrm{g})$ was digested in a $30 \mu \mathrm{l}$ reaction volume for $4 \mathrm{~h}$. Digested genomic DNA was loaded onto a $0 \cdot 8 \%$ agarose gel and electrophoresed at $15 \mathrm{~V}$ overnight. Southern hybridization was done using either linearized plasmid DNA or purified PCR products as probes which were radioactively labelled with $\left[\alpha_{-}{ }^{32} \mathrm{P}\right] \mathrm{dATP}$ using the Roche Random Primed DNA Labelling Kit. Following hybridization, the membrane was exposed to a Storage Phosphor Screen (Amersham Biosciences) for $1 \mathrm{~h}$. After exposure, the screen was scanned on a Storm 820 Phosphoimager (Molecular Dynamics) at a pixel size of $50 \mu \mathrm{m}$. Band intensities were calculated using the Image Quant 5.2 program (Molecular Dynamics). Plasmid copy number was calculated as a ratio of plasmid signal to chromosome signal. Copy number was determined for triplicate samples and a mean copy number is reported.

Protein purification. The $d n a A$ gene was PCR-amplified from genomic DNA using the AB26340 and AB26341 primers (Table 2) and cloned via engineered $B a m \mathrm{HI}$ and EcoRI restriction sites into the pET43a NusAHis 6 tag expression vector (Novagen) to create pTH1081. The pTH1081 plasmid was transformed into E. coli BL21 STAR (Stratagene) to create the protein overexpression strain J1027. This strain was grown at $37^{\circ} \mathrm{C}$ in $5 \mathrm{ml} \mathrm{LB}$ broth containing $50 \mu \mathrm{g}$ ampicillin $\mathrm{ml}^{-1}$ and subcultured into $100 \mathrm{ml} \mathrm{LB}$ broth with antibiotic. The culture was grown to an $\mathrm{OD}_{600}$ of 0.6 at $37^{\circ} \mathrm{C}$ and then IPTG was added to a final concentration of $0.3 \mathrm{mM}$. Following incubation for an additional $2.5 \mathrm{~h}$ at $30^{\circ} \mathrm{C}$, the cells were collected and resuspended in $10 \mathrm{ml}$ ice-cold resuspension buffer $(50 \mathrm{mM}$ $\mathrm{NaH}_{2} \mathrm{PO}_{4}, \mathrm{pH} 8 \cdot 0,500 \mathrm{mM} \mathrm{NaCl}, 10 \mathrm{mM}$ imidazole). Lysozyme was added to a $150 \mu \mathrm{g} \mathrm{ml}^{-1}$ final concentration and incubated on ice for approximately $30 \mathrm{~min}$. The cell suspension was then sonicated twice with a Branson Sonifier Cell Disruptor with a $1 / 8^{\prime \prime}(2.7 \mathrm{~mm})$ tapered probe for $20 \mathrm{~s}$ at a power level of 3.5. Lysates were kept on ice between sonications. The crude lysate was centrifuged at 15000 r.p.m. to remove insoluble material.

His-tagged protein was purified from the soluble cell lysate as a batch purification. Soluble lysate was incubated with $1 \mathrm{ml}$ equilibrated Ni-NTA resin (Qiagen) at $4{ }^{\circ} \mathrm{C}$ on a rotator for $1 \mathrm{~h}$. The sample was then spun in a swinging bucket rotor at 2000 r.p.m. for $3 \mathrm{~min}$ in a Clay Adams Dynac I centrifuge to pellet the resin and most of the supernatant was removed. The collected resin was added to a Bio-Rad Poly-Prep chromatography column and the flow-through was collected. The resin was then washed with $2 \mathrm{ml}$ ice-cold resuspension buffer and then $2 \mathrm{ml}$ ice-cold wash buffer \#1 (50 mM NaH${ }_{2} \mathrm{PO}_{4}$, pH $8 \cdot 0,500 \mathrm{mM} \mathrm{NaCl}, 20 \mathrm{mM}$ imidazole). The resin was then washed with $4 \mathrm{ml}$ ice-cold wash buffer \#2 $\left(50 \mathrm{mM} \mathrm{NaH}_{2} \mathrm{PO}_{4}, \mathrm{pH} 8 \cdot 0,500 \mathrm{mM}\right.$ $\mathrm{NaCl}, 40 \mathrm{mM}$ imidazole). The fusion protein was eluted from the column with $1 \mathrm{ml}$ ice-cold elution buffer $\left(50 \mathrm{mM} \mathrm{Na}_{2} \mathrm{PO}_{4}, \mathrm{pH} 8 \cdot 0\right.$, $500 \mathrm{mM} \mathrm{NaCl}, 250 \mathrm{mM}$ imidazole). The eluate $(1 \mathrm{ml})$ was added to a pre-soaked Pierce $3 \cdot 5 \mathrm{~K}$ Slide-A-Lyser with a cold syringe. Dialysis was carried out overnight at $4{ }^{\circ} \mathrm{C}$ in $4 \mathrm{l}$ buffer containing $50 \mathrm{mM} \mathrm{NaH}_{2} \mathrm{PO}_{4}$ $(\mathrm{pH} 8.0)$ and $300 \mathrm{mM} \mathrm{NaCl}$. The protein sample was removed from the dialysis cartridge and $0.5 \mu \mathrm{l}$ thrombin $\left(1.5 \mathrm{U}^{-1}\right.$; Novagen $)$ was added. Following incubation at room temperature for $2.5 \mathrm{~h}$, the reaction was added to a Bio-Rad Poly-Prep column, the flow-through was collected and the resin was washed with $0.5 \mathrm{ml}$ resuspension buffer, $0.5 \mathrm{ml}$ wash buffer \#1, $0.5 \mathrm{ml}$ wash buffer \#2; finally the NusA tag was eluted with $0.5 \mathrm{ml}$ elution buffer. Collected samples were analysed by SDS-PAGE.

Electrophoretic mobility shift assay. Probe DNA ( 100-200 bp purified PCR product) was quantified visually on a $1.8 \%$ agarose gel. One picomole of $5^{\prime}$ termini was then end-labelled with $\left[\gamma-{ }^{32} \mathrm{P}\right]$ ATP using T4 polynucleotide kinase (New England Biolabs). Following the labelling reaction, probes were purified with a QIAquick PCR Purification Kit (Qiagen). Specific activity of the labelled probe was calculated using a liquid scintillation counter.

The binding reaction was set up as described by Schaper \& Messer (1995). In a microfuge tube on ice the following were mixed (in this order): $4 \mu \mathrm{l} 5 \times$ binding buffer $(100 \mathrm{mM}$ HEPES-KOH, $\mathrm{pH} 8 \cdot 0$, $25 \mathrm{mM}$ magnesium acetate, $5 \mathrm{mM} \mathrm{Na}{ }_{2}$ EDTA, $20 \mathrm{mM}$ DTT, $25 \mathrm{mg}$ BSA $\mathrm{ml}^{-1}, 1 \%$ Triton X-100, $25 \%$ glycerol), $\mathrm{ddH}_{2} \mathrm{O}, 0 \cdot 4 \mu \mathrm{l}$ ATP

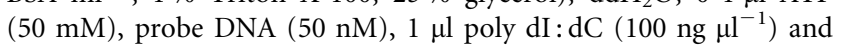
purified DnaA $(100-500 \mathrm{nM})$ in a total reaction volume of $20 \mu \mathrm{l}$. The reaction was incubated on ice for $10 \mathrm{~min}$ and then at room temperature for $20 \mathrm{~min}$. The reactions were loaded onto a $4 \%$ polyacrylamide gel and electrophoresed at $14 \mathrm{~V} \mathrm{~cm}^{-1}(252 \mathrm{~V})$ for $10 \mathrm{~min}$ and then $9 \mathrm{~V} \mathrm{~cm}^{-1}(162 \mathrm{~V})$ for $2 \cdot 5 \mathrm{~h}$ at room temperature. The gel was dried and exposed to Kodak Scientific Imaging Film and a Storage Phosphor Screen for quantification.

Environmental scanning electron microscopy. For glutaraldehyde fixation, several colonies were used to inoculate $2 \mathrm{ml} \mathrm{LBmc}$ with $30 \mu$ gentamicin $\mathrm{ml}^{-1}$ and the culture was grown to an $\mathrm{OD}_{600}$ of $0 \cdot 5$. The culture was pelleted in a microfuge tube and the supernatant was removed. The pellet was then resuspended in $1 \mathrm{ml} 0 \cdot 2 \mathrm{M}$ sodium cacodylate buffer $(\mathrm{pH} 7 \cdot 4)$. One millilitre of $0 \cdot 2 \mathrm{M}$ sodium cacodylate buffer containing $5 \%$ glutaraldehyde $(\mathrm{pH} 7 \cdot 4)$ was added, thus changing the effective concentration of glutaraldehyde to $2.5 \%$, and the tubes were inverted a couple of times and left for $1 \mathrm{~h}$ at room temperature.

For slide preparation, a cover glass was mounted on an aluminium ESEM stub with conductive glue (equal parts white Elmers glue and colloidal graphite) making sure that a line of conductive glue was made from the edge of the glue spot to the edge of the cover glass and just around to the sample side of the glass. The mounted cover glass was air-dried for $30 \mathrm{~min}$ and then coated with a $5 \mathrm{~nm}$ layer of gold using a Sputter Coater. The glutaraldehyde fixed

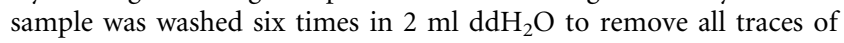
salt. Then, $1 \mu \mathrm{l}$ resuspended sample was spotted onto the gold-coated glass slide and the spot was allowed time to air dry. For visualization and image capturing the stub was placed into an Electroscan 2020 Environmental Scanning Electron Microscope and set to Wet mode. Samples were viewed at $2 \cdot 4-4 \cdot 0$ Torr with an accelerating voltage of $20-30 \mathrm{keV}$. Various magnifications were used and images were saved as TIFF files. 
Table 2. Oligonucleotides used in this study

Restriction sites that were engineered into the primers are shown in bold.

\begin{tabular}{|c|c|}
\hline Oligonucleotide name & Sequence $\left(5^{\prime} \rightarrow 3^{\prime}\right)$ \\
\hline AB24853 & AAGAATTCCAGCCGGCGAAGCGCCAG \\
\hline AB24854 & CCGAATTCCCACGACAAGGATGACGATGG \\
\hline AB26340 & CGCGGATCCATGCGGATGAATTTGGCG \\
\hline AB26341 & CGCGAATTCCTATTCGTTGATCAGTCGC \\
\hline AB27527 & GCCAAGCTTCTGCAGCACAACCGAGC \\
\hline AB27528 & GGCGAATTCTTAGGTGTCGCGTCATCG \\
\hline AB27526 & GCCGAATTCCTGCAACATTCCTACTCTCC \\
\hline dnaA32AS & AATGAATTCCCTCCAGGTGCCGTCGCC \\
\hline AB29675 & GAGCTCTATTCGTTGATCAGTCGCTTC \\
\hline AB29744 & AATCTAGATAACTGAAATTGGAAGGCGGCAAGATGCG \\
\hline AB30423 & GTAGAATTCTCAGGCGGTTTCCAGGTAGTCGC \\
\hline AB31447 & GCGGACGGATGCGATCCGCCGCCGGACCGGCTCG \\
\hline AB31448 & CGAGCCGGTCCGGCGGATCGCATCCGTCCGC \\
\hline AB31449 & CGCAGATCGACTCCTCACAGGAACCGCAAACTCCCG \\
\hline AB31450 & CGGGAGTTTGCGGTTCCTGTGAGGAGTCGATCTGCG \\
\hline AB31451 & GGCCATGAGTCTTGTATGCCCGGGCAAGAGATTTCCGG \\
\hline AB31452 & CCGGAAATCTCTTGCCCGGGCATACAAGACTCATGGCC \\
\hline AB32750 & GCTGTTTTTGTCCCGCCCAACAGACCGCGGAGAATTGCG \\
\hline AB32751 & CGCAATTCTCCGCGGTCTGTTGGGCGGGACAAAAACAGC \\
\hline AB32323 & TAGAATTCCATCAGCCAGATGGGGG \\
\hline AB32324 & ATGAATTCCACGCAATTCTCCGCGG \\
\hline ML700 & GTTTGCGGTTCCTGTGGATGAGG \\
\hline ML701 & CTCCGCGGTCTGTTGATAAGGC \\
\hline ML702 & GATGCGTTTCGCTCACTTGCCG \\
\hline ML703 & GCAAACTCCCGATCGCCGGC \\
\hline ML1182 & GTTTGCGGTTCCTGTGAGGAGTC \\
\hline ML1183 & CTCCGCGGTCTGTTGGGCG \\
\hline ML1817 & TAGAATTCCCTTTCATCGCGATCCTCGAACG \\
\hline ML1818 & ATGAATTCCGCGGTTCGCTCTATCTAAGCC \\
\hline ML2444 & ATGAATTCGAGGTCGTCCGGTTGCCCG \\
\hline ML2443 & ATGAATTCGCGCCTTGATCCACAGATAGAGG \\
\hline ML2445 & TAGAATTCGGTCGACGATCGTGTAGAGTACG \\
\hline ML2796 & CCGCCATCCAGGAGATCACCGC \\
\hline ML2797 & CCATCGCGGTCGCTGCCTTTGC \\
\hline ML3257 & CCTTGCCACGCTCGTGTCAATCC \\
\hline ML3258 & AACTCGAGTGCCGTCGCCAAATTCATCCG \\
\hline ML3852 & GCAATGATGTGGAGCGCCTTGACAGATAGAGGTCGTCCGG \\
\hline ML3853 & CCGGACGACCTCTATCTGTCAAGGCGCTCCACATCATTGC \\
\hline
\end{tabular}

\section{RESULTS AND DISCUSSION}

\section{Sequence analysis of predicted oric reveals hallmark features of chromosomal replication origins}

The origin of replication on the S. meliloti chromosome has been predicted to be approximately $400 \mathrm{~kb}$ from $d n a A$ and adjacent to hemE on the basis of GC skew (Capela et al., 2001) and this corresponds to the same location as the well studied chromosome origin from C. crescentus (Marczynski \& Shapiro, 1992; Marczynski et al., 1995; Brassinga \& Marczynski, 2001). The C. crescentus chromosome origin is located $\sim 5 \mathrm{~kb}$ from the $d n a A$ gene region, a sequence with a similar genetic arrangement to the $S$. meliloti dnaA region (Brassinga et al., 2001). This fadB1-rpsT-dnaA region is unusual in that it deviates from the rnpA-rmpH-dnaAdnaN-recF-gyrB-rnpA structure linked to many bacterial chromosome origins (Yoshikawa \& Ogasawara, 1991; Ogasawara \& Yoshikawa, 1992). Interestingly, the parBparA-gidA-gidB-thdF gene cluster located $\sim 70 \mathrm{~kb}$ from the C. crescentus oriC is within $8 \mathrm{~kb}$ of the predicted S. meliloti oriC. We examined the predicted $S$. meliloti oriC region for features characteristic of bacterial chromosome origins. The most obvious feature found was an exceptionally AT-rich ( $\sim 30 \mathrm{~mol} \% \mathrm{G}+\mathrm{C}$ over $80 \mathrm{nt}$ ) region contrasting with the 
(a)

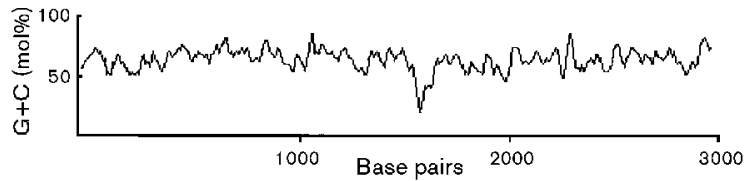

(b)

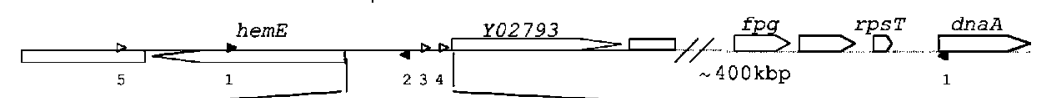

CAGCCAGATGGGGGGAGGGGTGAGCGCTCTCCCGCTCAAAACCTCCAGCACTTTGCGATGCGTTTCGCTCACTTGCCGCTTC CTAAICTAAAAATAAAACTGAATTTATAAGGTTTCTATTTCTTAGAGTCGGTGGGTATCAAGGATTAAAATCAATCCTCATC CTATCCAGTCCGCGTCAATCTCCGGCAAAGAGGCGGGAGAGATTCCGGCCGAATTGCGCGGTAAGCGGGGAAACCCGGTAAA ACACTGCAGAGTCAGCCCCITGCCGGCGATCGGGAGTTTGCGGTTCCTGTGGATGAGGAGTCGATCTGCGTGACAATITGTC GTGGCCATGAGTCTTGTCCACATGCCCGGGCAAGAGATTTCCGGTTAGGTGTCAGATGTGAACAAGTCGCCGCTTTTCCACT TGCCIGAAGCCAGGCGCCGCCGTTAGCIGTTTTTGTCCCGCCTTATCAACAGACCGCGGAGAATTGC

(c)

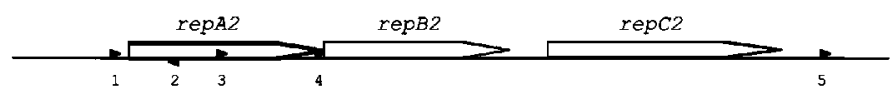

(d)

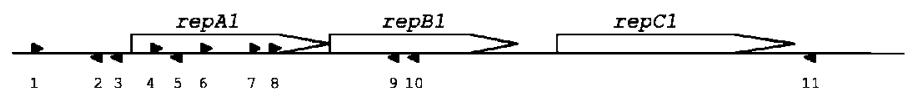

(e) oric

$\begin{array}{lrr} & \text { box } 1 & \text { TCATCCGCC } \\ & 2 & \text { TCATCCACA } \\ & 3 & \text { TTGTCCACA } \\ & 4 & \text { TTATCAACA } \\ \text { dnaA promoter } & 5 & \text { TGATCCACA } \\ & & \\ \text { repA2B2C2 } & \text { box } 1 & \text { TCATCCACA } \\ & & \\ & \text { box } 1 & \text { TCATCCACA } \\ & 2 & \text { CCATACGTA } \\ & 3 & \text { TCATCCACA } \\ & 4 & \text { TCATCCGCA } \\ \text { repA1B1C1 } & 5 & \text { TCATACGAC } \\ & & \\ & \text { box } & \text { TTATCCGAC } \\ & 2 & \text { TTTTACAAA } \\ & 3 & \text { CTCTCCAAA } \\ & 4 & \text { TTCTCCGTC } \\ & 5 & \text { TCCTCCATC } \\ & 6 & \text { CTCTCCGCC } \\ & 7 & \text { CTTTCCGCC } \\ & 8 & \text { TCTTACGAC } \\ 9 & \text { CTCTCCGCC } \\ & 10 & \text { CCATCCATC } \\ & 11 & \text { TCTTACAAA }\end{array}$

Fig. 1. $A G+C$ content graph of a $3 \mathrm{~kb}$ region encompassing the $S$. meliloti oriC region (a), and the location of putative DnaA-binding sites that match the expanded $E$. coli DnaA box consensus sequence $[(T / C)(T / C)(A / T / C) T(A / C) C(A / G)(A / C /$ T)(A/C) Schaefer \& Messer, 1991] in the S. meliloti origins of replication for the chromosome (b) (the sequence of the hemEY02793 intergenic region is provided with predicted DnaA shown in bold), (c) pSymA and (d) pSymB. Closed triangles represent $9 / 9$ matches and open triangles represent $8 / 9$ matches to the consensus sequence. The sequences of the putative DnaA boxes are provided in (e). The numbers below the DnaA boxes are how the binding sites are referred to in this study and are the numbers to the left of the sequence in (e).

flanking DNA and the rest of the chromosome which has a $\mathrm{G}+\mathrm{C}$ content of $62 \mathrm{~mol} \%$ (Fig. 1a). In E. coli, Bramhill \& Kornberg (1988b) showed that duplex opening occurred in the AT-rich region of oriC and presumably the lower double-stranded thermodynamic stability in this region promotes strand dissociation.

DnaA-binding sites are a consistent feature of bacterial oriCs. Sequences recognized by DnaA have been most extensively studied in E. coli and these 9 bp sequences seem relatively conserved amongst bacteria. We scanned the predicted $S$. meliloti oriC region for matches based upon the expanded $E$. coli consensus sequence $(\mathrm{T} / \mathrm{C})(\mathrm{T} / \mathrm{C})(\mathrm{A} / \mathrm{T} /$ C) $\mathrm{T}(\mathrm{A} / \mathrm{C}) \mathrm{C}(\mathrm{A} / \mathrm{G})(\mathrm{A} / \mathrm{C} / \mathrm{T})(\mathrm{A} / \mathrm{C})$ (Schaefer \& Messer 1991). As shown in Fig. 1(b), five putative DnaA boxes were identified in the $3 \mathrm{~kb}$ oriC region. An additional box was also found in the dnaA gene region. This DnaA box (box 5, Fig. 1b) is an $8 / 9$ bp match to the E. coli consensus sequence and is an exact match to an experimentally identified DnaA box found in the $C$. crescentus chromosome origin (Marczynski \& Shapiro, 1992). DnaA box 3 (also an $8 / 9$ bp match to the consensus) is identical to the sequences of DnaA boxes found in chromosome origins from Streptomyces spp. (Majka et al., 2001) and Micrococcus luteus (Fujita et al., 1990).

Since the initiation of replication of the megaplasmid origins may also be subject to regulation by DnaA, the rep $A B C$ replicator regions for the $\mathrm{pSymA}$ and $\mathrm{pSymB}$ megaplasmids were also scanned for DnaA-binding sites. As shown in Fig. 1(c), five putative DnaA boxes were identified in the pSymA repABC region. Interestingly, DnaA box 2, found in the hemE-Y02793 intergenic region, is found twice in the pSymA replicator region, once 158 bp upstream of the translational start site of repA2 and again inside the repA2 ORF. Eleven DnaA-binding sites were predicted in the pSymB repABClocus (Fig. 1d). It has been documented that only the repC ORF and sequence downstream of repC is necessary for repABC plasmid replication (Ramirez-Romero et al., 2000) and thus the origin of replication must be encoded either within repC or just downstream of the gene. This work predicts a single DnaA box in the sequence downstream of repC in both megaplasmid replicator regions and this box may therefore serve a role in recruiting the cellular replication machinery to the megaplasmid origins. However, the distribution of these putative DnaA boxes appears to be biased to upstream of or within the repA1 gene ( 8 of 11 predicted sites in the region). DnaA may possibly be involved in regulating repABC gene expression. There is no experimental evidence for the involvement of DnaA in repABC plasmid replication, but this work might point to such a role.

\section{Autonomous replication of the DNA region encompassing the predicted oriC}

Exploiting the ability of a cloned sequence to support autonomous replication of a normally non-replicating plasmid in the host cell has been a successful strategy for isolating the chromosome origins from Enterobacter aerogenes, Klebsiella pneumoniae (Harding et al., 1982), Erwinia carotovora (Takeda et al., 1982), Vibrio harveyi (Zyskind 
et al., 1983), Pseudomonas aeruginosa, Pseudomonas putida (Yee \& Smith, 1990) and Streptomyces lividans (ZakrzewskaCzerwinska \& Schrempf, 1992). We used this strategy to examine whether the previously predicted $S$. meliloti oriC region could support autonomous replication. For this purpose a $3 \mathrm{~kb}$ region encompassing the AT-rich region, the hemE and Y02793 genes, and the five putative DnaA boxes was amplified by PCR from S. meliloti genomic DNA using primers AB24853 and AB24854. This DNA was cloned into pUCP30T (a plasmid that cannot replicate in S. meliloti) to form plasmid pTH838 (see Fig. 3b). pTH838 was transferred from E. coli donor cells into a recA ${ }^{-}$derivative of $S$. meliloti (Rm5004) via conjugation. The ability of pTH838 to promote the formation of transconjugant colonies on medium containing an antibiotic $\left(60 \mu \mathrm{g}\right.$ gentamicin $\left.\mathrm{ml}^{-1}\right)$ to select for its presence is indicative of autonomous replication. The pTH838 plasmid transferred into both Rm5004 and wild-type Rm1021 cells and transconjugants were obtained at a frequency of $10^{-1}$ per recipient cell. The high transfer frequency into both recipient strains reflects an ability of pTH 838 to autonomously replicate because the recA mutation in Rm5004 prevents homologous recombination of the plasmid with the hemE locus on the chromosome. To our surprise, every time this mating experiment was performed, both small and large S. meliloti transconjugant colonies arose on selective medium after incubation. Both small and large Rm5004(pTH838) transconjugants colonies were purified three times on selective medium, then tested for the presence of an autonomously replicating plasmid by Southern blot hybridization. A single small colony and a single large colony (done in triplicate) was used to inoculate LB and total DNA was prepared following growth for $36 \mathrm{~h}$. As a control, total DNA was prepared from a pUCP30T cointegrant strain RmK569 (a wild-type
Rm1021 derivative in which a single copy of pUCP30T has integrated at the $p s t S$ locus). Total transconjugant genomic DNA was restricted and probed in a Southern blot with labelled pUCP30T. pTH838 DNA was detected as a single restriction fragment and this is indicative of the plasmid being maintained as a closed circular molecule in the transconjugant cells. Two restriction fragments hybridized with the pUCP30T probe in the control strain RmK569. Similarly, integration of pTH838 into the chromosomal hemE locus would result in two restriction fragments, whereas only a single fragment was observed (data not shown), revealing that pTH838 is an autonomously replicating plasmid.

The conjugal transfer of pTH838 into Rm5004 resulted in both small and large transconjugants with approximately 50 times more small than large colonies. The rate and extent to which colonies form upon selection medium is at least in part dependent on the phenotypic level of resistance conferred by the antibiotic resistance gene, and the resistance gene dosage (i.e. copy number of plasmid carrying the gene) might influence this parameter. To investigate whether the difference in colony size was due to differences in the copy number of the pTH838 plasmid, we carried out a Southern blot hybridization to assess the relative amounts of the autonomously replicating pTH838 plasmid in both the small and large transconjugants. Large and small colonies were streak-purified to single colonies three times and total DNA was prepared in triplicate from cultures inoculated with the purified strains, designated SmK1012 and SmK1013 for small and or large colonies, respectively. The DNA was restricted with HindIII, transferred onto nitrocellulose and probed with the $477 \mathrm{bp}$ PCR fragment (amplified with primers $\mathrm{AB} 32323$ and AB32324) of the

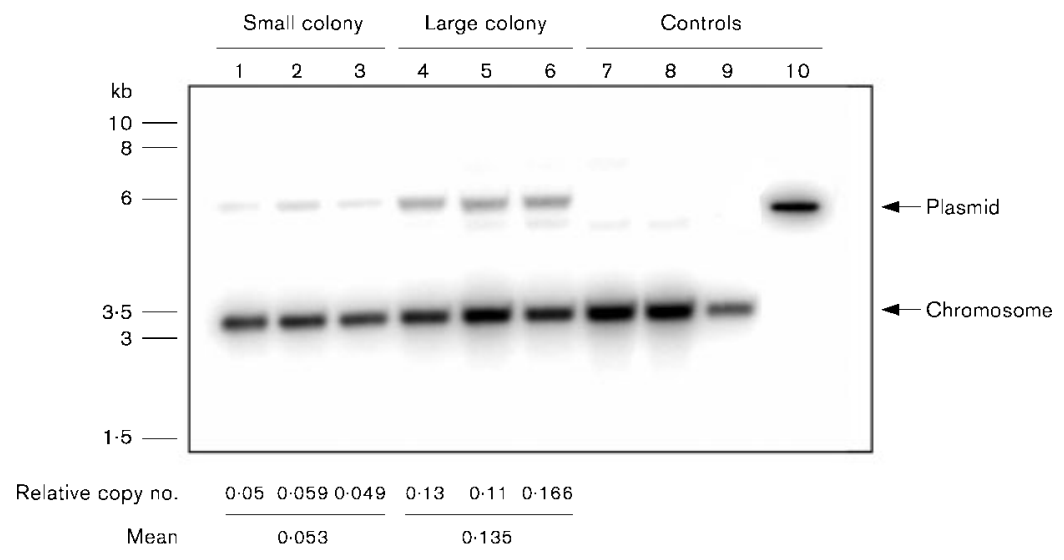

Fig. 2. Southern blot used to assess the copy number of the PTH838 oriC plasmid in S. meliloti. Hindlll-restricted total DNA prepared from cultures inoculated with either a single small Rm5004(pTH838) transconjugant colony or a single large Rm5004(pTH838) transconjugant colony. Lanes: 1 , small \#1; 2 , small \#2; 3, small \#3; 4, large \#1; 5, large \#2; 6, large \#3; 7, RmK569(ФpUСР30T pstS); 8, Rm1021 (wild-type); 9, Rm5004; 10, Hindlll-restricted pTH838 plasmid DNA. A PCR product of the $477 \mathrm{bp}$ hemE-Y02793 intergenic region (using primers $A B 32323$ and $A B 32324)$ was randomly prime-labelled and used as a probe. The $5.8 \mathrm{~kb}$ band is probe-hybridized with plasmid DNA and the $3.4 \mathrm{~kb}$ band corresponds to the chromosomal signal. Intensities of the bands were determined and relative copy number was calculated as a ratio of plasmid to chromosome signal. The mean copy number was calculated from the three independent colonies tested. 
hemE-Y02793 intergenic region (Fig. 2). The intensities of the plasmid signal $(5 \cdot 8 \mathrm{~kb})$ and the chromosome signal $(3.5 \mathrm{~kb})$ were quantified with a phosphoimager. A ratio of plasmid signal: chromosome signal was determined for each transconjugant sample and then the three ratios for each of the small and large strains were used to calculate a mean number of plasmid molecules per chromosome. The mean copy number of the three small transconjugants was determined to be 0.053 plasmids per chromosome and the mean copy number of the three large transconjugants was $0 \cdot 135$ plasmids per chromosome. Thus the large colonies contained approximately twice as much autonomously replicating pTH838 plasmid DNA as the small colonies.

It is not uncommon to observe altered colony morphologies in bacterial cells containing plasmid copies of the host chromosome origin. Colony morphologies consistent with the delayed colony development phenotype reported for $S$. meliloti in this work have been observed in C. crescentus cells harbouring minichromosomes (Marczynski et al., 1995). Mutations that impair the replication of $C$. crescentus minichromosomes do so in a way that leads to a reduction of the copy number of the autonomously replicating plasmid and results in a delayed growth phenotype on selective medium. This parallels our observation that Rm5004(pTH8383) transconjugant colony size directly correlates with the copy number of the pTH838 minichromosomes.

To validate the calculated pTH838 copy number of less than one, K1012 and K1013 and the control strain RmK569 (Rm1021 with a single copy of pUCP30T that has integrated at the $p s t S$ locus) were grown in LB with antibiotic selection to mid-exponential phase and plated onto LB plates without added antibiotic. Two hundred colonies were then patched back onto selective medium and incubated at $30^{\circ} \mathrm{C}$ for

Table 3. Transconjugation frequencies per recipient and donor resulting from the transfer of pTH838 from $S$. meliloti into $E$. coli

Three S. meliloti strains were used as donors; E. coli MT620 was used as the recipient and MT616 was used as the mobilizing strain in the triparental mating. The mating spot was resuspended, serial-diluted and plated onto selective medium. Transconjugants were selected for on LB agar with $20 \mu \mathrm{g}$ rifampicin $\mathrm{ml}^{-1}$ and $10 \mu \mathrm{g}$ gentamicin $\mathrm{ml}^{-1}$, recipients were selected for on LB agar with $20 \mu \mathrm{g}$ rifampicin $\mathrm{ml}^{-1}$ and donors were selected for on LB agar with $200 \mu \mathrm{g}$ streptomycin $\mathrm{ml}^{-1}$ and $60 \mu \mathrm{g}$ gentamicin $\mathrm{ml}^{-1}$. The transconjugation frequency for S. meliloti K569 and E. coli MT616 was $0\left(<10^{-8}\right.$ per donor $)$.

\begin{tabular}{|lcc|}
\hline Donor & \multicolumn{2}{c|}{ Transconjugation frequency } \\
\cline { 2 - 3 } & $\begin{array}{c}\text { Transconjugants/ } \\
\text { E. coli recipient }\end{array}$ & $\begin{array}{c}\text { Transconjugants/ } \\
\text { S. meliloti donor }\end{array}$ \\
\hline S. meliloti K1013 & $0 \cdot 23$ & $0 \cdot 13$ \\
S. meliloti K1012 & $0 \cdot 28$ & $0 \cdot 13$ \\
\hline
\end{tabular}

4 days. A total of 20 of the $200(0 \cdot 1)$ patches and 13 of the $200(0 \cdot 065)$ patches were gentamicin-resistant from the K1013 and K1012 cultures, respectively. As expected, all 200 of the RmK569 patches maintained gentamicin resistance because of the stability of the chromosomally integrated copy of pUCP30T. These values are very close to the mean copy number calculated from the Southern blot (Fig. 2), 0.053 vs 0.065 for the small transconjugants and 0.135 vs $0 \cdot 1$ for the large transconjugants. These ratios represent the fraction of cells in the cell population growing in the presence of gentamicin that actually contain a pTH838 plasmid molecule or the gentamicin $3^{\prime}$-acetyltransferase protein encoded by the pTH838 plasmid.

We employed a second indirect method to establish that pTH838 was autonomously replicating in Rm5004. The method is based on the premise that autonomously replicating plasmids, but not integrated plasmids, can be readily transferred from $S$. meliloti to E. coli. Thus we tested strains K1012 [Rm5004(pTH838) small transconjugant], K1013 [Rm5004(pTH838) large transconjugant] and strain RmK569 (as a control) for their ability to transfer pTH838 (as monitored by gentamicin resistance) to E. coli. The results from these experiments (Table 3 ) clearly showed a high frequency of transfer of gentamicin resistance from the Rm5004(pTH838) transconjugants K1012 and K1013 to E. coli $\left(>10^{-1}\right.$ per donor). In contrast no transfer of the integrated copy of pUCP30T in RmK569 to E. coli was detected $\left(<10^{-8}\right.$ per donor). Restriction analysis of plasmid DNA prepared from gentamicin-resistant E. coli transconjugant cells confirmed that the transferred plasmid was pTH838 (data not shown). These data demonstrate that pTH838 is capable of autonomous replication and therefore represents a mini-derivative of the chromosomal basic replicon.

\section{Delineation of the minimal sequence that supports autonomous replication}

As described above, the nucleotide sequence coincident with the predicted oriC encodes hallmark features of chromosomal origins, including an AT-rich sequence and five putative DnaA boxes, and a $3 \mathrm{~kb}$ region encompassing these features is able to autonomously replicate in S. meliloti cells. To delineate the ori $C$ region required to allow the suicide plasmid pUCP30T to replicate in S. meliloti, various subfragments from the insert in pTH838 were subcloned into pUCP30T. The resulting plasmids were examined for their ability to replicate in Rm5004 (Fig. 3b). The sequence encompassing the AT-rich region and DnaA boxes 2, 3 and 4 (pTH1245) was not sufficient for autonomous replication (transconjugant colony formation). The $5^{\prime}$ limit of the sequence required for autonomous replication was mapped to within $19 \mathrm{bp}$ (the difference between pTH1451 and pTH1452, and the difference between pTH1453 and pTH1454) and within this essential $19 \mathrm{bp}$ is the predicted DnaA box 5. The $3^{\prime}$ limits required for transconjugant colony formation (pTH1454) extends $250 \mathrm{bp}$ into the Y02793 ORF and thus the plasmid copy of Y02793 is not 
(a)
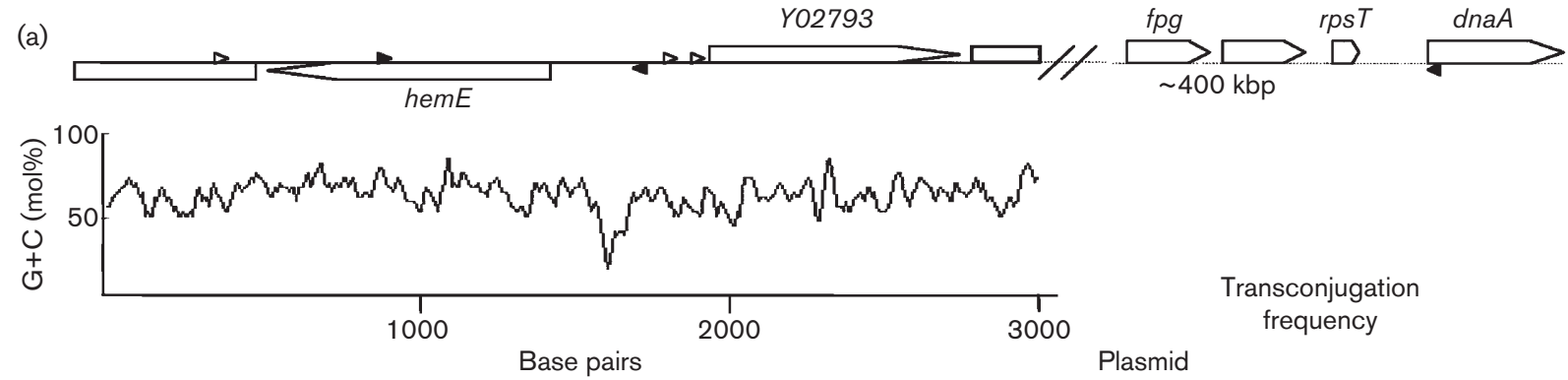

(b)

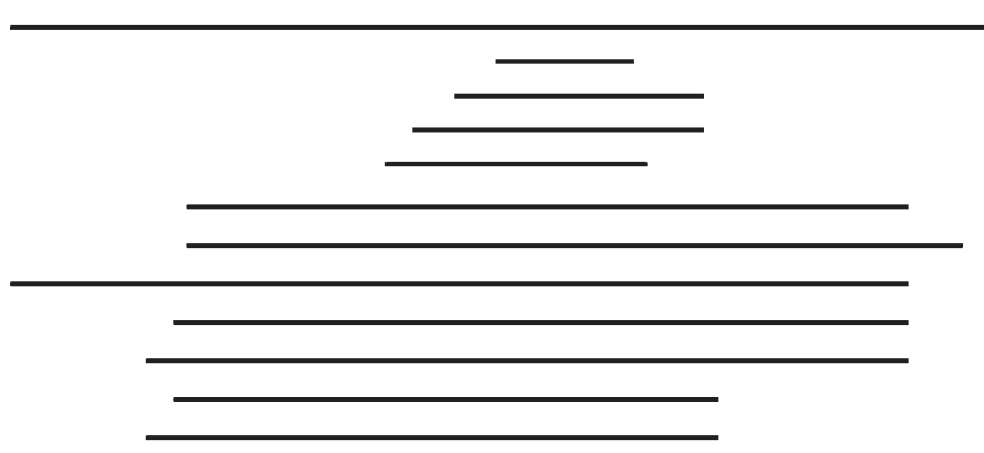

(c)

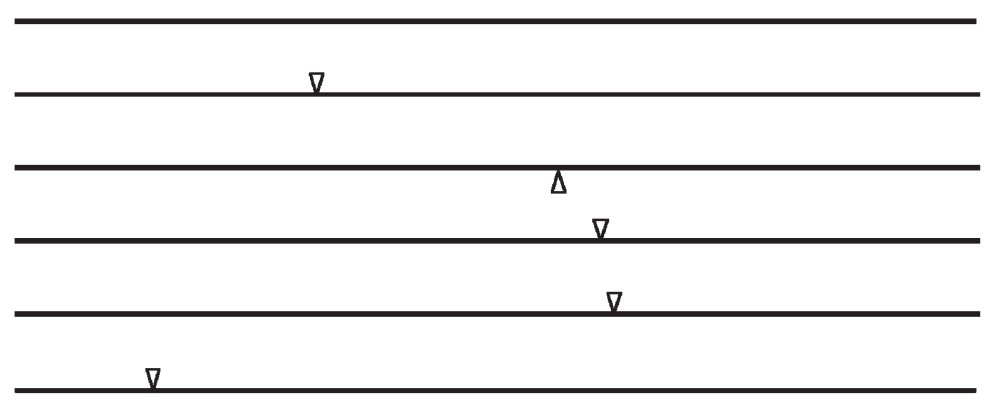

\begin{tabular}{|c|c|c|}
\hline \multicolumn{3}{|c|}{$\begin{array}{l}\text { Transconjugation } \\
\text { frequency }\end{array}$} \\
\hline \multicolumn{3}{|l|}{ Plasmid } \\
\hline pTH838 & & $10^{-1}$ \\
\hline pTH1245 & & 0 \\
\hline рTH879 & & 0 \\
\hline pTH880 & & 0 \\
\hline pTH881 & & 0 \\
\hline pTH1416 & & $10^{-7}$ \\
\hline pTH1442 & & $10^{-6}$ \\
\hline pTH1443 & & $10^{-1}$ \\
\hline pTH1451 & & $10^{-7}$ \\
\hline pTH1452 & & $10^{-1}$ \\
\hline pTH1453 & & $10^{-7}$ \\
\hline pTH1454 & & $10^{-1}$ \\
\hline \multicolumn{3}{|c|}{ Recipients } \\
\hline Plasmid & $\mathrm{Rm} 1021$ & Rm5004 \\
\hline pTH838 & $10^{-1}$ & $10^{-1}$ \\
\hline pTH1205 & $10^{-1}$ & $10^{-1}$ \\
\hline pTH1206 & $10^{-6}$ & 0 \\
\hline pTH1207 & $10^{-5}$ & 0 \\
\hline pTH1253 & $10^{-6}$ & 0 \\
\hline pTH1518 & $10^{-1}$ & $10^{-1}$ \\
\hline
\end{tabular}

Fig. 3. (a) A genetic map of the S. meliloti chromosomal origin of replication showing the hemE and YO2793 loci, and the $d n a A$ gene region of the $S$. meliloti chromosome which is located $400 \mathrm{~kb}$ away from oriC. A G $+\mathrm{C}$ content graph indicates the location of an exceptionally AT-rich region in the hemE-Y02793 intergenic region. DnaA boxes that match the expanded E. coli consensus sequence (T/C)(T/C)(A/T/C)T(A/C)C(A/G)(A/C/T)(A/C) (Schaefer \& Messer, 1991) are shown with dark triangles and boxes that match the consensus $8 / 9$ are represented with open triangles. (b) Subclones of the $3 \mathrm{~kb}$ origin in pTH838 are scored for their ability to generate transconjugant colonies when cloned into a suicide plasmid (pUCP30T) and transferred into an S. meliloti rec $A^{-}$strain (Rm5004). (c) Location of site-directed mutations in the S. meliloti oriC. The locations of the site-directed deletions are indicated with an inverted triangle. Transconjugation frequencies are provided in the accompanying table for transfer into Rm1021 and Rm5004.

required for autonomous replication. The minimal size of the S. meliloti oriC is $1802 \mathrm{bp}$ and this is much larger than the $437 \mathrm{bp}$ C. crescentus minimal chromosome origin (Marczynski \& Shapiro, 1992). It may be that the hemE ORF itself is not required for replication, but only the DnaA box located downstream of hemE and thus deletion of the intervening $956 \mathrm{bp}$ hemE gene would reduce the size of the S. meliloti oriC to $846 \mathrm{bp}$. The minimal nucleotide sequence required to support autonomous replication of the suicide plasmid pUCP30T suggests that the functional S. meliloti oriC sequence may be defined by the distribution of DnaA boxes that flank the AT-rich region.
We therefore examined the importance of the predicted DnaA boxes to replication by using a mutagenesis approach. The five DnaA boxes identified in PTH838 were mutated by oligonucleotide site-directed mutagenesis. The mutations in DnaA boxes 5, 2, 3 and 4 were 4 bp deletions and the mutation in DnaA box 1 was a 3 bp deletion (Fig. 3c). Plasmids carrying mutations in boxes 2, 3 and 4 lost the ability to autonomously replicate in $S$. meliloti, suggesting that these sequences are required for replication of plasmidborne oriC (Fig. 3c). As expected, transconjugant colonies formed at a low frequency when mutant oriC plasmids were transferred into Rm1021, probably due to homologous 
recombination at the oriC genomic locus. Rm1021 was used as a control recipient in the replication assay to ensure that the oriC plasmids were still mobilizable after mutagenesis. The mutation in DnaA box 1 did not influence pTH 838 replication and, surprisingly, the mutation carried on pTH1518 (mutation in DnaA box 5) also did not abolish replication even though our deletion analysis (Fig. 3b) demonstrated that this sequence was essential for replication. It is possible that the removal of the $4 \mathrm{bp}$ in DnaA box 5 generated a sequence still capable of interacting with the replication initiator. DnaA box 5 ( $5^{\prime}$-TGATCCACA- $\left.3^{\prime}\right)$ is an $8 / 9$ bp match to the expanded E. coli DnaA box consensus (Fig. 1.); the site-directed mutation (deletion of GATC) in this predicted binding site generates $5^{\prime}$-TCACAGATA- $3^{\prime}$ and this sequence only deviates from the consensus sequence at positions 4 and 6 . In other words, the 4 bp deletion in box 5 may result in the reconstitution of a sequence that can still bind DnaA.

\section{DnaA binds to predicted binding sites in the hemE-Y02793 intergenic region}

The ability of DNA fragments carrying the various putative DnaA-binding sites to bind purified DnaA protein was examined in electrophoretic mobility shift assays. We tested mutations in putative DnaA-binding sites that abolish replication of plasmid-borne oriC for their influence on DnaA binding. The six DNA sequences that were used in DnaA-binding experiments included a $190 \mathrm{bp}$ probe (ML700/ML701) that contained all three predicted DnaA boxes in the hemE-Y02793 intergenic region (DnaA boxes 2, 3 and 4), a 178 bp probe (ML1182/ML1183) with the same sequence as the $190 \mathrm{bp}$ probe except with $4 \mathrm{bp}$ deletions in all three predicted DnaA boxes, a 117 bp probe (ML2796/ ML2797) containing DnaA box 5 downstream of hemE, a 197 bp fragment (ML3257/ML3258) from the dnaA promoter that contains a predicted DnaA box overlapping the translational start site of the $d n a A$ gene, a $233 \mathrm{bp}$ repA2 promoter probe (ML702/ML703) which includes a DnaA box with an exact match to DnaA box 2 in oriC and a 125 bp
repA1 promoter probe (AB27527/AB27526) containing two DnaA boxes.

Two complexes were resolved with the $190 \mathrm{bp}$ oriC probe as seen in Fig. 4; however, in some cases using this probe resulted in the formation of three complexes (data not shown), consistent with the number of binding sites in the probe. Three rounds of site-directed mutagenesis of pTH838 were required to introduce the three mutations needed to generate a template that could be used for PCR amplification of the 178 bp probe. DnaA did not interact with this target as it did with the wild-type sequence and thus it appears that the mutations created in the hemEY02793 intergenic region represent bona fide deletions in DnaA boxes (Fig. 3c). Only a weak interaction was observed with the 117 bp DnaA box 5 probe. Complexes were not detected with the $d n a A$ promoter probe or the repA1 promoter probe. DnaA did complex with the repA2 promoter probe, probably at the predicted DnaA box 158 bp upstream of the repA2 translational start site. DnaA has been implicated as a transcription factor as it autoregulates $d n a A$ gene expression (Atlung et al., 1985) and either represses or activates expression from several other genes (Messer \& Weigel, 1997). Thus the DnaA-binding site upstream of the repA2B2C2 operon may be biologically relevant such that expression of the pSymA genes encoded in the replicator region are transcriptionally coordinated with chromosome replication.

\section{Expression of S. meliloti DnaA in $E$. coli and S. meliloti results in a block in cell division}

DnaA seems to be conserved in bacteria as a regulator of replication initiation events at the chromosome origin and it has been reported that overexpression of DnaA in E. coli stimulates the initiation reaction at oriC (Atlung et al., 1987; Skarstad et al., 1989). This results in a loss of the correct timing in the cycle of replication initiation and leads to a block in cell division, thus generating filamentous cells (Pierucci et al., 1989). This block in cell division as a result of

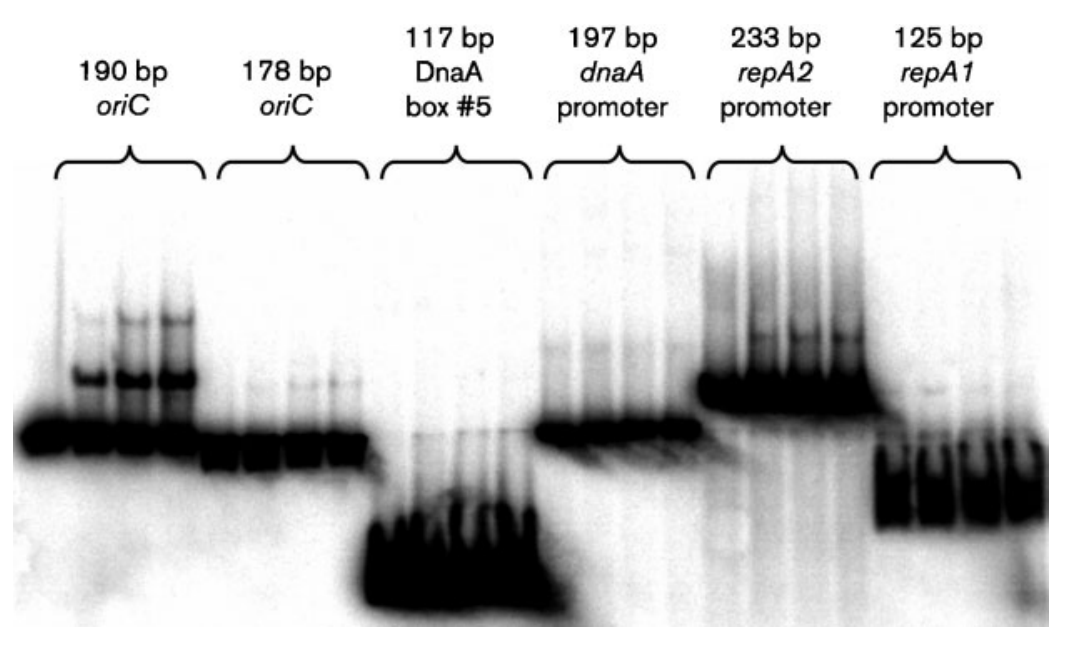

Fig. 4. Electrophoretic mobility shift assay with target DNA containing predicted DnaA boxes and purified S. meliloti DnaA. Several target DNA fragments were used in a binding reaction with purified DnaA. Three concentrations of protein were added to the binding reaction (100, 300 and $500 \mathrm{nM})$ and the DNA fragments were also loaded without added protein. The size and description of each labelled DNA fragment is indicated above the lanes. The first left-hand lane for each DNA target is DNA without protein added and the next three lanes (left to right) are the DNA target incubated with 100,300 and $500 \mathrm{nM}$ purified DnaA, respectively. 
increased DnaA levels has also been reported for $\mathrm{Myco}$ bacterium smegmatis (Greendyke et al., 2002). We examined whether DnaA would have similar consequences on $S$. meliloti cell morphology if overexpressed. To this end the dnaA gene and $20 \mathrm{bp}$ upstream of the predicted translational start (including a predicted ribosome-binding site) was PCR-amplified using primers AB29744 and AB29675. Primer AB29744 was designed with three engineered stop codons in all three reading frames to prevent a fusion to the Lac $\alpha$ peptide encoded in pBBR1MCS-5. The PCR product was cloned into pBBR1MCS-5 such that the $d n a A$ gene was under the transcriptional control of the E. coli lac promoter, generating plasmid pTH1091. The pTH1091 DnaA expression plasmid was transferred into wild-type $S$. meliloti Rm1021 and E. coli DH5 $\alpha$ and transconjugant cells were visualized with an environmental scanning electron microscope. Many more of the E. coli cells expressing S. meliloti DnaA appeared filamentous compared to the parent DH5 $\alpha$ (compare Fig. $5 \mathrm{a}$ and $\mathrm{b}$ ), suggesting that $S$. meliloti DnaA has some form of cross-functionality and can perturb cell division in other Proteobacteria. S. meliloti cells expressing DnaA from the plasmid promoter also displayed an apparent block in cell division, with many of the cells growing up to $15 \mu \mathrm{m}$ in length compared to the $1 \mu \mathrm{m}$ length of Rm1021 wild-type cells (compare Fig. $5 c$ and d). The $S$. meliloti filaments are complex and in most cases the cells display many branches with swollen areas flanked by regions that appear partially septated, as shown under higher magnification (Fig. 5e and f).

We cannot deduce the molecular mechanism underlying this phenotype; however, the morphological changes resulting from the plasmid-mediated expression of $S$. meliloti DnaA are very similar to the pleomorphic cell shape phenotype reported for $S$. meliloti cells overexpressing FtsZ or when treated with DNA-damaging agents (Latch \& Margolin, 1997). It would seem that the default pathway for a block in cell division that arises from perturbations in
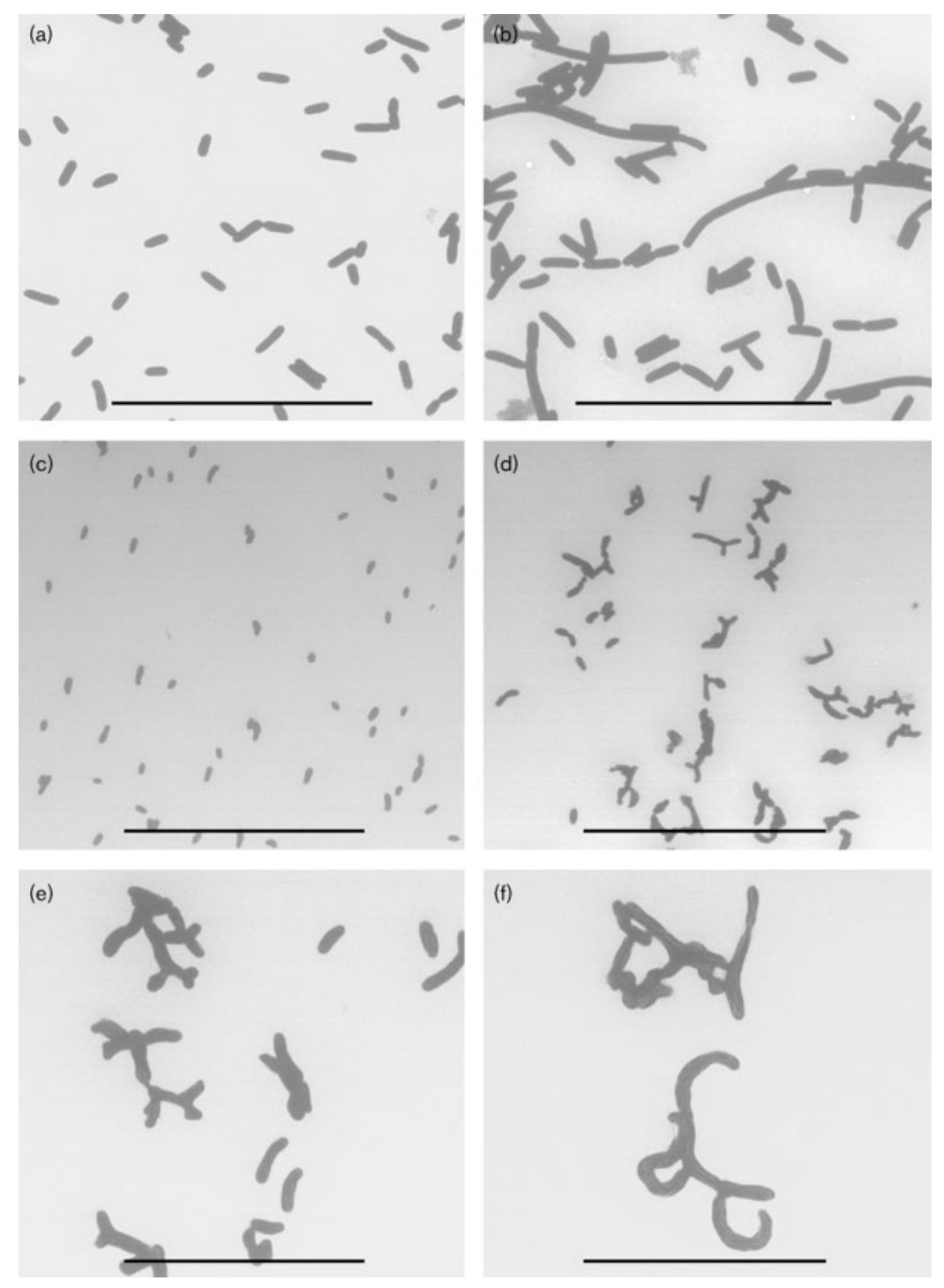

Fig. 5. Environmental scanning electron micrographs of $E$. coli and $S$. meliloti cells expressing S. meliloti DnaA from the E. coli lac promoter in the pBBR1MCS5 plasmid derivative, pTH1091. (a) shows $E$. coli $\mathrm{DH} 5 \alpha$ harbouring pBBR1MCS5 and (b) shows E. coli DH5 $\alpha$ carrying pTH1091. (c) shows wild-type Rm1021 harbouring the pBBR1MCS5 plasmid and (d), (e) and (f) are wild-type $\mathrm{Rm} 1021$ cells expressing DnaA from pTH1091. Bars, $25 \mu \mathrm{m}$ (a, b), $30 \mu \mathrm{m}$ (c, d) and $15 \mu \mathrm{m}$ (e, f). 
chromosome replication in this endosymbiont is a complex change in cell shape. Interestingly, many of the cells assume branched Y-shaped architectures that look very similar to the fully differentiated bacteroids found inside plant cells in root nodules.

Here we report the identification of a replication origin from the S. meliloti circular chromosome which represents the first such origin to be localized in the Rhizobiaceae and the second chromosome origin to be experimentally defined in the Alphaproteobacteria. This is the third autonomously replicating sequence to be identified in the S. meliloti genome. The other two sequences were isolated from the pSymB megaplasmid (Margolin \& Long, 1993; Chain et al., 2000). The S. meliloti oriC possesses the hallmark features of a bacterial chromosome origin, such as sequences that interact specifically with the replication initiator DnaA (DnaA boxes) flanking an exceptionally AT-rich region. Interestingly, the S. meliloti chromosome origin is located greater than $400 \mathrm{~kb}$ from the dnaA gene which, in other bacteria, is often closely linked to the replication origin. This explains why an autonomously replicating sequence was not detected in the vicinity of $d n a A$ in previous attempts to localize this replication origin (Margolin et al., 1995). S. meliloti transconjugant cells harbouring oriC plasmids display a delayed growth phenotype, perhaps explaining why a screen for autonomously replicating sequences encoded in the S. meliloti genome conducted by Margolin \& Long (1993) did not detect the chromosome origin.

Previous reports have demonstrated that requirements for minichromosome replication may be very different than those for the chromosomal origin. The necessity of certain DnaA-binding sites and DNA-bending proteins $\mathrm{HU}$ and IHF for oriC plasmid replication, but not for chromosome replication (Weigel et al., 2001; Asai et al., 1998), suggests that the plasmid-borne oriC may adopt a very different DNA topology than the chromosomal origin. It is possible that constraints on DNA topology in S. meliloti minichromosomes may cause a severe reduction in the number of replication initiation events occurring at oriC in pTH838 and thus result in copy numbers of much less than one per chromosome.

The copy numbers of plasmids encoding bacterial oriC sequences is quite diverse. The best characterized bacterial minichromosome from $E$. coli has a copy number of approximately 38 per cell (Lobner-Olesen et al., 1987), but this does not represent the typical situation. Plasmids replicating from the cloned Pseudomonas chromosome origin have been reported to be present at as low as $0 \cdot 7$ copies per cell (Yee \& Smith, 1990). The ColE1 replication origin has also been shown to exert a strong effect on the copy number of Mycobacterium tuberculosis minichromosomes and can reduce the copy number from approximately 17 to 0.6 plasmids per chromosome (Qin et al., 1999). The cause of this instability is unknown, but we do not rule out the possibility that the ColE1 replication origin present in
pUCP30T may be the cause of the low S. meliloti minichromosome copy number.

While we refer to the region identified in this report as the oriC, we note that direct experimental proof that replication of the S. meliloti chromosome initiates from this region has yet to be obtained. Similarly, the presumed replication origins for the pSymA and pSymB megaplasmids have yet to be experimentally verified. Such verification would seem to be very worthwhile and since this would require synchronization of cell division, these experiments could also address whether replication of the chromosome and two megaplasmids is coordinately regulated.

\section{ACKNOWLEDGEMENTS}

This work was primarily supported with grants from the Natural Sciences and Engineering Council of Canada to T. M. F. C. S. was also supported with funding from Genome Canada through the Ontario Genomics Institute and with funding from the Ontario research and development challenge fund to T.M.F.

\section{REFERENCES}

Asai, T., Bates, D. B., Boye, E. \& Kogoma, T. (1998). Are minichromosomes valid model systems for DNA replication control? Lessons learned from Escherichia coli. Mol Microbiol 29, 671-675.

Atlung, T., Clausen, E. S. \& Hansen, F. G. (1985). Autoregulation of the dnaA gene of Escherichia coli K12. Mol Gen Genet 200, 442-450.

Atlung, T., Lobner-Olesen, A. \& Hansen, F. G. (1987). Overproduction of DnaA protein stimulates initiation of chromosome and minichromosome replication in Escherichia coli. Mol Gen Genet 206, 51-59.

Bramhill, D. \& Kornberg, A. (1988a). A model for initiation at origins of DNA replication. Cell 54, 915-918.

Bramhill, D. \& Kornberg, A. (1988b). Duplex opening by DnaA protein at novel sequences in initiation of replication at the origin of the E. coli chromosome. Cell 52, 743-755.

Brassinga, A. K. \& Marczynski, G. T. (2001). Replication intermediate analysis confirms that chromosomal replication origin initiates from an unusual intergenic region in Caulobacter crescentus. Nucleic Acids Res 29, 4441-4451.

Brassinga, A. K., Siam, R. \& Marczynski, G. T. (2001). Conserved gene cluster at replication origins of the $\alpha$-Proteobacteria Caulobacter crescentus and Rickettsia prowazekii. J Bacteriol 183, 1824-1829.

Calcutt, M. J. \& Schmidt, F. J. (1992). Conserved gene arrangement in the origin region of the Streptomyces coelicolor chromosome. J Bacteriol 174, 3220-3226.

Capela, D., Barloy-Hubler, F., Gouzy, J. \& 25 other authors (2001). Analysis of the chromosome sequence of the legume symbiont Sinorhizobium meliloti strain 1021. Proc Natl Acad Sci U S A 98, 9877-9882.

Chain, P. S., Hernandez-Lucas, I., Golding, B. \& Finan, T. M. (2000). oriT-directed cloning of defined large regions from bacterial genomes: identification of the Sinorhizobium meliloti pExo megaplasmid replicator region. J Bacteriol 182, 5486-5494.

Finan, T. M., Kunkel, B., De Vos, G. F. \& Signer, E. R. (1986). Second symbiotic megaplasmid in Rhizobium meliloti carrying exopolysaccharide and thiamine synthesis genes. J Bacteriol 167, 66-72. 
Fujita, M. Q., Yoshikawa, H. \& Ogasawara, N. (1990). Structure of the $d n a A$ region of Micrococcus luteus: conservation and variations among eubacteria. Gene 93, 73-78.

Fujita, M. Q., Yoshikawa, H. \& Ogasawara, N. (1992). Structure of the dnaA and DnaA-box region in the Mycoplasma capricolum chromosome: conservation and variations in the course of evolution. Gene 110, 17-23.

Fuller, R. S., Kaguni, J. M. \& Kornberg, A. (1981). Enzymatic replication of the origin of the Escherichia coli chromosome. Proc Natl Acad Sci U S A 78, 7370-7374.

Fuller, R. S., Funnell, B. E. \& Kornberg, A. (1984). The DnaA protein complex with the $E$. coli chromosomal replication origin (oriC) and other DNA sites. Cell 38, 889-900.

Galibert, F., Finan, T. M., Long, S. R. \& 53 other authors (2001). The composite genome of the legume symbiont Sinorhizobium meliloti. Science 293, 668-672.

Greendyke, R., Rajagopalan, M., Parish, T. \& Madiraju, M. V. (2002). Conditional expression of Mycobacterium smegmatis dnaA, an essential DNA replication gene. Microbiology 148, 3887-3900.

Harding, N. E., Cleary, J. M., Smith, D. W., Michon, J. J., Brusilow, W. S. \& Zyskind, J. W. (1982). Chromosomal replication origins (oriC) of Enterobacter aerogenes and Klebsiella pneumoniae are functional in Escherichia coli. J Bacteriol 152, 983-993.

Jakimowicz, D., Majka, J., Messer, W. \& 8 other authors (1998). Structural elements of the Streptomyces oriC region and their interactions with the DnaA protein. Microbiology 144, 1281-1290.

Kovach, M. E., Elzer, P. H., Hill, D. S., Robertson, G. T., Farris, M. A., Roop, R. M. \& Peterson, K. M. (1995). Four new derivatives of the broad-host-range cloning vector pBBR1MCS, carrying different antibiotic-resistance cassettes. Gene 166, 175-176.

Latch, J. N. \& Margolin, W. (1997). Generation of buds, swellings, and branches instead of filaments after blocking the cell cycle of Rhizobium meliloti. J Bacteriol 179, 2373-2381.

Lobner-Olesen, A., Atlung, T. \& Rasmussen, K. V. (1987). Stability and replication control of Escherichia coli minichromosomes. J Bacteriol 169, 2835-2842.

Lobry, J. R. (1996). Asymmetric substitution patterns in the two DNA strands of bacteria. Mol Biol Evol 13, 660-665.

Mackiewicz, P., Zakrzewska-Czerwinska, J., Zawilak, A., Dudek, M. R. \& Cebrat, S. (2004). Where does bacterial replication start? Rules for predicting the oriC region. Nucleic Acids Res 32, 3781-3791.

MacLellan, S. R., Smallbone, L. A., Sibley, C. D. \& Finan, T. M. (2005). The expression of a novel antisense gene mediates incompatibility within the large $r e p A B C$ family of alpha-proteobacterial plasmids. Mol Microbiol 55, 611-623.

Majka, J., Zakrzewska-Czerwinska, J. \& Messer, W. (2001). Sequence recognition, cooperative interaction, and dimerization of the initiator protein DnaA of Streptomyces. J Biol Chem 276, 6243-6252.

Marczynski, G. T. \& Shapiro, L. (1992). Cell-cycle control of a cloned chromosomal origin of replication from Caulobacter crescentus. J Mol Biol 226, 959-977.

Marczynski, G. T., Lentine, K. \& Shapiro, L. (1995). A developmentally regulated chromosomal origin of replication uses essential transcription elements. Genes Dev 9, 1543-1557.

Margolin, W. \& Long, S. R. (1993). Isolation and characterization of a DNA replication origin from the 1,700-kilobase-pair symbiotic megaplasmid pSym-b of Rhizobium meliloti. J Bacteriol 175, 6553-6561.

Margolin, W., Bramhill, D. \& Long, S. R. (1995). The dnaA gene of Rhizobium meliloti lies within an unusual gene arrangement. J Bacteriol 177, 2892-2900.
Meade, H. M., Long, S. R., Ruvkun, G. B., Brown, S. E. \& Ausubel, F. M. (1982). Physical and genetic characterization of symbiotic and auxotrophic mutants of Rhizobium meliloti induced by transposon Tn5 mutagenesis. J Bacteriol 149, 114-122.

Messer, W. \& Weigel, C. (1997). DnaA initiator - also a transcription factor. Mol Microbiol 24, 1-6.

Moriya, S., Atlung, T., Hansen, F. G., Yoshikawa, H. \& Ogasawara, N. (1992). Cloning of an autonomously replicating sequence (ars) from the Bacillus subtilis chromosome. Mol Microbiol 6, 309-315.

Ogasawara, N. \& Yoshikawa, H. (1992). Genes and their organization in the replication origin region of the bacterial chromosome. Mol Microbiol 6, 629-634.

Paau, A. S., Lee, D. \& Cowles, J. R. (1977). Comparison of nucleic acid content in populations of free-living and symbiotic Rhizobium meliloti by flow microfluorometry. J Bacteriol 129, 1156-1158.

Pierucci, O., Rickert, M. \& Helmstetter, C. E. (1989). DnaA protein overproduction abolishes cell cycle specificity of DNA replication from oriC in Escherichia coli. J Bacteriol 171, 3760-3766.

Qin, M. H., Madiraju, M. V. \& Rajagopalan, M. (1999). Characterization of the functional replication origin of Mycobacterium tuberculosis. Gene 233, 121-130.

Ramirez-Romero, M. R., Soberon, N., Perez-Oseguera, A., TellezSosa, J. \& Cevallos, M. A. (2000). Structural elements required for replication and incompatibility of the Rhizobium etli symbiotic plasmid. J Bacteriol 182, 3117-3124.

Richter, S. \& Messer, W. (1995). Genetic structure of the dnaA region of the cyanobacterium Synechocystis sp. strain PCC6803. J Bacteriol 177, 4245-4251.

Richter, S., Hess, W. R., Krause, M. \& Messer, W. (1998). Unique organization of the dnaA region from Prochlorococcus marinus CCMP1375, a marine cyanobacterium. Mol Gen Genet 257, 534-541.

Salazar, L., Fsihi, H., De Rossi, E., Riccardi, G., Rios, C., Cole, S. T. \& Takiff, H. E. (1996). Organization of the origins of replication of the chromosomes of Mycobacterium smegmatis, Mycobacterium leprae and Mycobacterium tuberculosis and isolation of a functional origin from M. smegmatis. Mol Microbiol 20, 283-293.

Schaefer, C. \& Messer, W. (1991). DnaA protein/DNA interaction. Modulation of the recognition sequence. Mol Gen Genet 226, 34-40.

Schaper, S. \& Messer, W. (1995). Interaction of the initiator protein DnaA of Escherichia coli with its DNA target. J Biol Chem 270, 17622-17626.

Schaper, S., Nardmann, J., Luder, G., Lurz, R., Speck, C. \& Messer, W. (2000). Identification of the chromosomal replication origin from Thermus thermophilus and its interaction with the replication initiator DnaA. J Mol Biol 299, 655-665.

Schweizer, H. P., Klassen, T. R. \& Hoang, T. (1996). Improved methods for gene analysis and expression in Pseudomonas. In Biology of Pseudomonas, pp. 229-237. Edited by T. Nakazawa, K. Furukawa, D. Haas \& S. Silver. Washington, DC: American Society for Microbiology.

Skarstad, K., Lobner-Olesen, A., Atlung, T., von Meyenburg, K. \& Boye, E. (1989). Initiation of DNA replication in Escherichia coli after overproduction of the DnaA protein. Mol Gen Genet 218, 50-56.

Smith, D. W., Yee, T. W., Baird, C. \& Krishnapillai, V. (1991). Pseudomonad replication origins: a paradigm for bacterial origins? Mol Microbiol 5, 2581-2587.

Takeda, Y., Harding, N. E., Smith, D. W. \& Zyskind, J. W. (1982). The chromosomal origin of replication (oriC) of Erwinia carotovora. Nucleic Acids Res 10, 2639-2650.

Weigel, C., Messer, W., Preiss, S., Welzeck, M., Morigen \& Boye, E. (2001). The sequence requirements for a functional Escherichia coli 
replication origin are different for the chromosome and a minichromosome. Mol Microbiol 40, 498-507.

Yee, T. W. \& Smith, D. W. (1990). Pseudomonas chromosomal replication origins: a bacterial class distinct from Escherichia coli-type origins. Proc Natl Acad Sci U S A 87, 1278-1282.

Yoshikawa, H. \& Ogasawara, N. (1991). Structure and function of DnaA and the DnaA-box in eubacteria: evolutionary relationships of bacterial replication origins. Mol Microbiol 5, 2589-2597.
Zakrzewska-Czerwinska, J. \& Schrempf, H. (1992). Characterization of an autonomously replicating region from the Streptomyces lividans chromosome. J Bacteriol 174, 2688-2693.

Zyskind, J. W., Cleary, J. M., Brusilow, W. S., Harding, N. E. \& Smith, D. W. (1983). Chromosomal replication origin from the marine bacterium Vibrio harveyi functions in Escherichia coli: oriC consensus sequence. Proc Natl Acad Sci $U$ S A 80, $1164-1168$. 